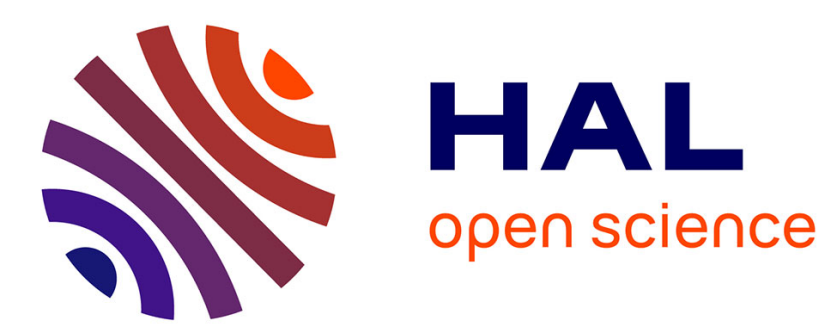

\title{
Experimental and numerical study of compression after impact of sandwichs structures with metallic skins
}

\author{
Y. Aminanda, Bruno Castanié, J-J. Barrau, P. Thevenet
}

\section{To cite this version:}

Y. Aminanda, Bruno Castanié, J-J. Barrau, P. Thevenet. Experimental and numerical study of compression after impact of sandwichs structures with metallic skins. Composites Science and Technology, 2009, 69 (1), pp.50. 10.1016/j.compscitech.2007.10.045 . hal-00563494

\section{HAL Id: hal-00563494 \\ https://hal.science/hal-00563494}

Submitted on 6 Feb 2011

HAL is a multi-disciplinary open access archive for the deposit and dissemination of scientific research documents, whether they are published or not. The documents may come from teaching and research institutions in France or abroad, or from public or private research centers.
L'archive ouverte pluridisciplinaire HAL, est destinée au dépôt et à la diffusion de documents scientifiques de niveau recherche, publiés ou non, émanant des établissements d'enseignement et de recherche français ou étrangers, des laboratoires publics ou privés. 


\section{Accepted Manuscript}

Experimental and numerical study of compression after impact of sandwichs structures with metallic skins

Y. Aminanda, B. Castanié, J-J. Barrau, P. Thevenet

PII: S0266-3538(07)00440-X

DOI: 10.1016/j.compscitech.2007.10.045

Reference: CSTE 3889

To appear in: Composites Science and Technology

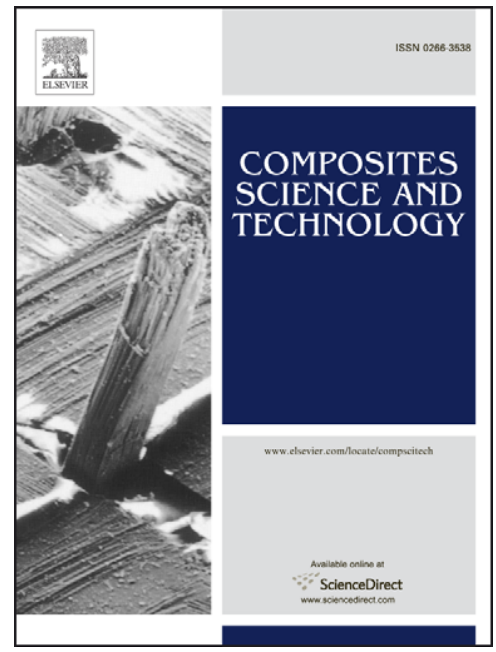

Received Date: $\quad 14$ May 2007

Accepted Date: 11 October 2007

Please cite this article as: Aminanda, Y., Castanié, B., Barrau, J-J., Thevenet, P., Experimental and numerical study of compression after impact of sandwichs structures with metallic skins, Composites Science and Technology (2007), doi: 10.1016/j.compscitech.2007.10.045

This is a PDF file of an unedited manuscript that has been accepted for publication. As a service to our customers we are providing this early version of the manuscript. The manuscript will undergo copyediting, typesetting, and review of the resulting proof before it is published in its final form. Please note that during the production process errors may be discovered which could affect the content, and all legal disclaimers that apply to the journal pertain. 


\title{
EXPERIMENTAL AND NUMERICAL STUDY OF COMPRESSION AFTER IMPACT OF SANDWICHS STRUCTURES WITH
}

\author{
METALLIC SKINS
}

Y.Aminanda*, B.Castanié**, J-J.Barrau*** et P.Thevenet ${ }^{+}$

* Mechanical Engineering, Dept of IIUM, J1.Gombak P.O Box 1050728 Kuala Lumpur

\author{
Malaysia \\ ** IGMT, Laboratoire Structure, Supaéro. BP 403231055 Toulouse cedex 4. \\ Corresponding author : Tel 33 (0) 5.62.17.81.16 Fax 33 (0) 5.61.55.81.78 \\ bruno.castanie@supaero.fr \\ *** IGMT, Université Paul Sabatier, Bat 3PN 31062 Toulouse, France Supaéro. BP \\ 403231055 Toulouse cedex 4 \\ ${ }^{+}$EADS CRC, 12 rue Pasteur, BP 76,92152 Suresnes Cedex, France
}

\begin{abstract}
A finite element model is proposed to determine the residual print of sandwiches structures with Nomex honeycomb core and metallic skins indented by a spherical indenter and to simulate its behavior when this indented structure is subjected to lateral compressive loading (known as CAI/ Compression after impact). The particularities of this model rely on representing the honeycomb with a grid of non-linear springs which its behavior law is calibrated from uniform compression test. This simple model, after
\end{abstract}


integrating the cycle behavior law of honeycomb, allow predicting the geometry of residual print with a good precision. This model is then developed to propose a complete computation from indentation, residual print geometry to lateral compressive loading after indentation (CAI). This model allows also predicting numerically the residual strength of structure in CAI and the elliptical evolution of residual print geometry during CAI loading. A good correlation with test results is obtained except for the very small residual print depth.

KEYWORDS: B: IMPACT BEHAVIOR MODELLING, C : SANDWICH

\section{INTRODUCTION}

The study presented in this paper is a development of ones that have been done in ([1], [2]), in which a phenomenological analysis of damage modes of cellular structure have been presented. This phenomenological study has given a possibility to propose a simple model based on grid of non-linear spring to represent Nomex honeycomb subjected to uniform compressive load. Thereafter this model has been generalized to the study of indentation on sandwiches structures with metallic skin and a good correlation with test results has been obtained. Even if the final goal of the study was to model the indentation (quasi-static or low energy and low speed impact) on aeronautic type of sandwiches structures, so with composite skins, the use of metallic skins has been taken first to avoid the complexity and difficulty of modeling the composite skins damage modes [3].

Experiments have shown that the depth of residual print after indentation would not be corresponded to the maximal depth one $[4,8]$. However, in aviation regulation point of 
view, limit of detectable damage called BVID (barely visible Impact damage) after impact is defined and beyond this limit the structure should be designed for damage tolerance [4]. Thus, it is important to be able to determine first this residual print geometry which, in our knowledge, only a small number of studies in term of numerical and analytical model have been done on this subject [6-8]. Palazotto [6] has proposed a finite elements model of impact using 3 loops of iterative computation to determine successively damage on honeycomb, damage on composite skin and geometry of print. Horrigan [8] has proposed a continuum damage model to model the behavior of honeycomb. But, due to the continuum approach, the core damaged area could not be predicted correctly. In [1], honeycomb is represented by a grid of vertical springs which behavior law in compression is calibrated from uniform compressive loading experiments. In this paper, the law is developed further by integrating the cycled behavior (compression loading and unloading) of honeycomb that allows simulating the defect recovery of honeycomb after compression and the residual print geometry of the sandwiches structures after indentation.

This preliminary study is important because the residual print geometry after indentation has a direct relation with residual strength of indented sandwiches structures subjected to lateral compressive loading (CAI) [3, 4]. Several analytical models have been proposed to simulate the CAI phenomena [5] and, recently, Lacy [7] has proposed a numerical model where the initial damage geometry after impact has been measured directly from the specimen by destructive and non-destructive inspection. He used also a fixed law behavior for composite skins on the impacted area (50\% of module degradation). In general, all references concerning CAI study shows that the phenomena have not been 
known totally and some developments were necessary to be developed before its application in industry. The proposed model in this paper will integrate the complete computation from indentation, residual print geometry after indentation to compression after indentation (CAI). With this complete computation, the initial conditions before CAI computation in term of geometry, core damage and state of stress on skin will be identified and will be used to determine the residual strength of sandwiches structures subjected to CAI loading.

\section{Description of CAI Tests}

Specimens (figure 1 and table 1) are prepared by taking care a high surface smoothness and high dimensional precision $(+-0.01 \mathrm{~mm})$ which are the necessary conditions to obtain a correct uniform compressive test. The standard dimension of specimen is $150 \times 100 \mathrm{~mm}$. Resins are mould into both extremities of each specimen. To transfer properly the compressive load, 2 plates of brass with $1 \mathrm{~mm}$ of thickness are added as reinforcement at resin-nomex junction area. These specimens are previously indented on flat support (figure 2) and the indentation is carried out by imposing the displacement with a constant speed of $0.5 \mathrm{~mm} / \mathrm{mn}$. A spherical indenter made from steel with radii of $57,25 \mathrm{~mm}$ is used and several depths of maximum indentation $d=0 ; 0.5 ; 1 ; 1.5$ and $2 \mathrm{~mm}$ are realized to obtain a different damage area.

For compression (CAI) tests after indentation, test supports and specimens correspond to the AIRBUS standards (figure 3) that allow us to compare test results with the industrial ones. These supports and specimens are realized within the laboratory. In order to observe the evolution of damage geometry in term of its depth and its form during 
compressive loading, a method of 3D Image correlation using 2 cameras is employed (figure 3).

Strains gages are also used to observe the distribution of compression flux on both skins. Compressive load acting on the specimens are measured directly from INSTRON machine and the displacement of compression surface is measured using LVDT displacement measurement.

\section{Analysis of CAI test results}

Analysis of indentation test results was described in detail in [1] and will not be presented again in this paper. The curves of compressive load in function of its displacement for 5 indented specimens with different depth of indentation $d$ are plotted on figure 4 . For all of the specimens, the initial stiffness is identical and corresponds to the elastic behavior of skins. Analytical calculation shows that the point where the slope is changed just after the elastic behavior of skins coincides with the yield limit of skin.

Thus, it seems that at the beginning of compression, the dimension of damage area caused by indentation do not play a significant influence. The second slope is also practically identical for all specimens. This slope seems to be controlled by plastic behavior of skins. As the force of compression increases, an inflexion is observed just after the passage of maximum force which can be qualified as the residual strength of indented structure. This residual strength depends on the depth of the maximum indentation $d$. It decreases significantly with the increasing of the maximum indentation depth $d$ so when the damage in the core due to indentation is more important (figure 5). 
The evolution of the damage geometry (more precisely: residual print geometry) after indentation in term of several parameters such as its depth and its radii about lateral axis $a$ and longitudinal axis $b$ during the compressive loading is studied. The elliptical evolution of residual print geometry during loading is described on figure 6 and the evolution of damage geometry in term of the parameters mentioned before in function of compressive load is drawn also in figure 6. By observation from 3D Image correlation, the evolution of damage area can be described as follows:

- In the region of elastic behavior of skins, the circle form of residual print geometry after indentation remains circle and its depth almost does not vary.

- At the beginning of plastic behavior of skins, the form of the print begin to be elliptical progressively in the direction of lateral axis a. In the same time, in the direction of longitudinal axis b, no evolution is observed. The print depth is also observed to be increased progressively.

- Approaching maximum compressive load (residual strength of the structure), the print depth increases brutally, the same observation is also obtained for the evolution of radii about the lateral axis a which finally it reaches the edges of specimen. It's interesting to note also that the deflection of non-indented skin below the indented area increases also rather quickly.

For specimen that was indented only with maximum indentation depth $d=0,5 \mathrm{~mm}$ and which has a corresponding residual print depth of $0.1 \mathrm{~mm}$, the evolution of its damage geometry is quite different. This specimen, with only $2 \%$ of decreasing in term of residual strength, behaves almost as a non-indented specimen. However, the elliptical evolution of the damage geometry is also observed with a brutal progression when 
approaching the maximum compressive loading. This behaviour is similar from all qualitative points of view to that observed for a thin composite skin [9].

\section{Modeling of Compression after indentation (CAI) tests}

Globally, the same finite element model using implicit SAMCEF software that was used for the study of indentation [1] is employed (see Figure 7). The principals of the model are as follows:

- Indented skin is modeled by Mindlin type of element. This skin has free boundary conditions except at the position of the CAI test supports (vertical blockages). These blockages did not exist during indentation (figure 3). However, literatures showed that indentation caused a local damage area and for the size of specimen used for this study, the boundary conditions are not sensitive. This insensitivity is confirmed by a posteriori numerical computation. The compression law for the brass skin was obtained from tests on a virgin (non-indented) sandwich specimen and it appeared that car the yied stress on compression was $110 \mathrm{MPa}$ instead of the $100 \mathrm{MPa}$ on traction one and also the hardening law was slightly different.

- Hexagonal Nomex honeycomb is modeled by a grid of non-linear vertical springs placed geometrically on the same position of honeycomb verticals edges. Its law behavior is obtained experimentally from cycled compression uniform loading test on a small block of Nomex honeycomb (figure 8). Until $0.4 \mathrm{~mm}$ of displacement of uniform compression surface, compression unloading give a linear return of displacement with the same slope as compression one. Beyond that displacement, the return is no more linear 
(ellipse with the power of 2.8). By assumption, the hysteresis behavior found from the test is judged negligible and is not taken into account in FEM computation.

-Non-indented skin had to be modeled with the same model as indented skin. But almost all the degree of freedom are blocked except its in-plan displacement (in this case translation in $\mathrm{x}$ and $\mathrm{y}$ ) to allow non-indented skin deforming like a membrane during compression.

The lower skin was added because the distribution of the forces between the two skins varies as the defect progresses. It is obvious that the discrete model used before cannot directly represent the bending of the sandwich and thus the out-of-plane displacement of the non-indented skin. In fact, all the degrees of freedom of this skin are locked except for the displacements in the plane of the sandwich ( $\mathrm{x}$ and $\mathrm{y}$ axis) so that the skin can deform during the compression. However, this assumption is justified because the deflection of non-indented skin below the indented area measured during tests is very small and only become significant when the compressive load approaches the maximum one. Also globally, the deflection of non-indented skin still remains negligible compared to the depth of indented area. Moreover, the computation is more robust numerically when the boundaries conditions are conserved for complete computation involving different phases.

The load acting on structure is simulated by imposing first a vertical displacement of the indenter toward $\mathrm{Z}$ negative (compression loading) and $\mathrm{Z}$ positive (compression unloading) then followed by imposing the displacement on the edges of structure to simulate the lateral compression load(CAI) on indented structure (figure 9). 


\section{Test/Computation comparison}

Test/computation comparison during indentation phase are described on figure 10 for the case of maximum indentation $d=2 \mathrm{~mm}$. The curve of indentation force in function of indenter displacement is plotted on figure 10(a) and the profile of residual print about longitudinal axis $\mathrm{b}$ is plotted on figure 10 (b). The depth of residual print obtained from computation is $1.42 \mathrm{~mm}$ whereas $1.32 \mathrm{~mm}$ is obtained from test measurement that give the difference of $7 \%$. For all specimens, the difference of residual print between computation and test varies from $25 \%$ for the smallest indentation depth $(d=0.5 \mathrm{~mm})$ to 7 $\%$ for the deepest one $(d=2 \mathrm{~mm})$. The curves obtained from the indentation test are correctly simulated by computation [1] also globally for the geometry of residual print after indentation.

In compressive loading after indentation phase, the evolution of residual print is studied by analyzing the 2 parameters: depth of residual print and profile about major axis $a$. The minor axis does not vary significantly. Test/Computation comparisons for these 2 parameters are represented in figure 11 for the specimen indented with maximum indentation $d=1.5 \mathrm{~mm}$. Globally, numerical computations give the same evolution as test results. The small difference at the beginning of compression is due to the difference of residual print depth between computation and test from the previous phase. However, there is also a significant difference in term of final depth of damage area (in the maximum compressive load region) because the out-of-plan deflection of the structure is not taken into account in computation. In the other hand, the maximum compressive load, so the residual strength of indented sandwich structure is perfectly simulated. Also, the 
evolution of damage area in term of its profile about major axis is perfectly simulated by computation (figure 11).

A good correlation between test results and computations in term of print geometry evolution and maximum compressive load is obtained for almost all indented specimens except in the case of small indentation $d=0.5 \mathrm{~mm}$ (figure 12). For this test, the depth of residual print is so small with only $0.15 \mathrm{~mm}$. Investigations are carrying out to know whether the initial geometry defect such as skin curving would stabilize the indented structure whereas this defect is not taken into account in computation. It is also possible that, regarding the smallness of residual print depth, the difference comes from the insufficiency of refined mesh that creates early numerical instability.

We can note that the reactions of these springs (number 1 and 2) are very weak and increase a little bit during the elliptical progression of print geometry. We can see it for the spring placed just in the circumference of initial damage area before compression loading (spring number 1). It is interesting to note that the collapse of this spring after reaching its maximum force, more or less precedes the brutal evolution of elliptical damage geometry that is produced when the neighbor spring (number 2) placed about lateral axis $a$ just after spring 1 collapses in its turn.

To describe mechanical behavior of print geometry evolution during compressive load, it is interesting to analyse the reaction of springs placed about major axis and in the circumference of residual print. This can be done by extracting the force of the corresponding spring $\left(n^{\circ} 1,2,3\right.$, figure 13$)$ for the computation case $d_{\max }=1.5 \mathrm{~mm}$. The reaction of these springs (1 à 3) is seen to be very weak and do not increase much during 
denting and the gradual extension of the ellipse. After a drop of spring force which is probably due to appearance of little bump that stretch the springs, a brutal increase of force until reaching its maximum (peak force of spring) is observed and quickly reaches the critical force (the peak) for the first spring at the periphery $\left(\mathrm{n}^{\circ} 1\right)$. It is very interesting to note that the collapse of this first edge occurs only shortly before the abrupt progression of the ellipse which takes place when the second edge (spring $n^{\circ} 2$ ) situated on the major axis of the ellipse, collapes in its turn. Numerically, it is shown here that the advance of the defect coincides with the physical phenomenon of edge buckling. So the collapse of the edge situated on the major axis of the ellipse can be proposed as the criterion of structural failure. This criterion is interesting as it could be used as an inexpensive calculation in industry to predict a breaking force that is not too conservative. These criteria should also avoid an expensive and complex numerical computation of damage propagation in term of CPU time in the case of composite skins.

\section{CONCLUSIONS}

A finite elements model is proposed to simulate the behavior of indented sandwiches structures with Nomex honeycomb core and metallic skins subjected to compressive loading ( CAI ). The model has globally a good correlation with test results for the specimens studied in term of residual strength of structure and evolution of damage area (residual print geometry) except for the very smalls indented area below BVID. The original modeling of honeycomb using a grid of non-linear springs allows describing and explaining the mechanical behavior of the damage area evolution during compressive 
loading on indented structure (CAI) and proposing failures criteria of the structure. This study will be continued by integrating the degradations of carbon laminate skins.

\section{REFERENCES}

[1] Aminanda,Y., Castanie, B., Thevenet, P., Barrau, J-J., ' Modelisation de l'indentation des structures sandwichs a peaux métalliques’, Méc Ind 2005; 6: 487-498.

[2] Aminanda,Y., Castanie, B., Thevenet, P., Barrau, J-J., Guedras-Degeorges, D., 'Experimental analysis and Modelling of Honeycomb Cores Crush', Appl Comp Mat 2005;12 (3-4): 213-227

[3] Abrate S. Localized impact on sandwich structures with laminated facings, Appl .Mech Rev 1997;50(2): 69-82.

[4] Guedra-Degeorges D, Thevenet P, Maison S, 'Damage Tolerance of sandwich structures', Proceeding of EUROMECH 360 colloqium, Kluwer Academic Pub, 1997.

[5] Minguet P.J,' A model for predicting behavior of impact-damaged minimum gage sandwich panels under compression', Proc of the AIAA/ASME/ASCE/AHS/ASC $32^{\text {nd }}$ structure, struc dyn and material conference, 1997, 423-439.

[6]Herup E.J, Palazotto A.N. Low-velocity impact damage initiation in graphite/epoxy/nomex honeycomb-sandwich plates', Comp Sci Tech 1997;57: 15811598.

[7] Lacy T.E, Hwang Y. Numerical modeling of impact-damaged sandwich composites subjected to compression-after-impact loading, Comp Struct 2003 (61): 115-128.

[8] Horrigan D.P.W., Aitken R.R., Moltschaniswskyj G. Modelling of crushing due to impact in honeycomb sandwich". J Sand Struct Mat 2000 (2):131-151. 
[9] Castanié B., Barrau J.J., Jaouen J.P., Rivallant S., 2004. Combined Shear/Compression Structural Testing of Asymmetric Sandwich Structures. Exp mech 44(5), 461-472.

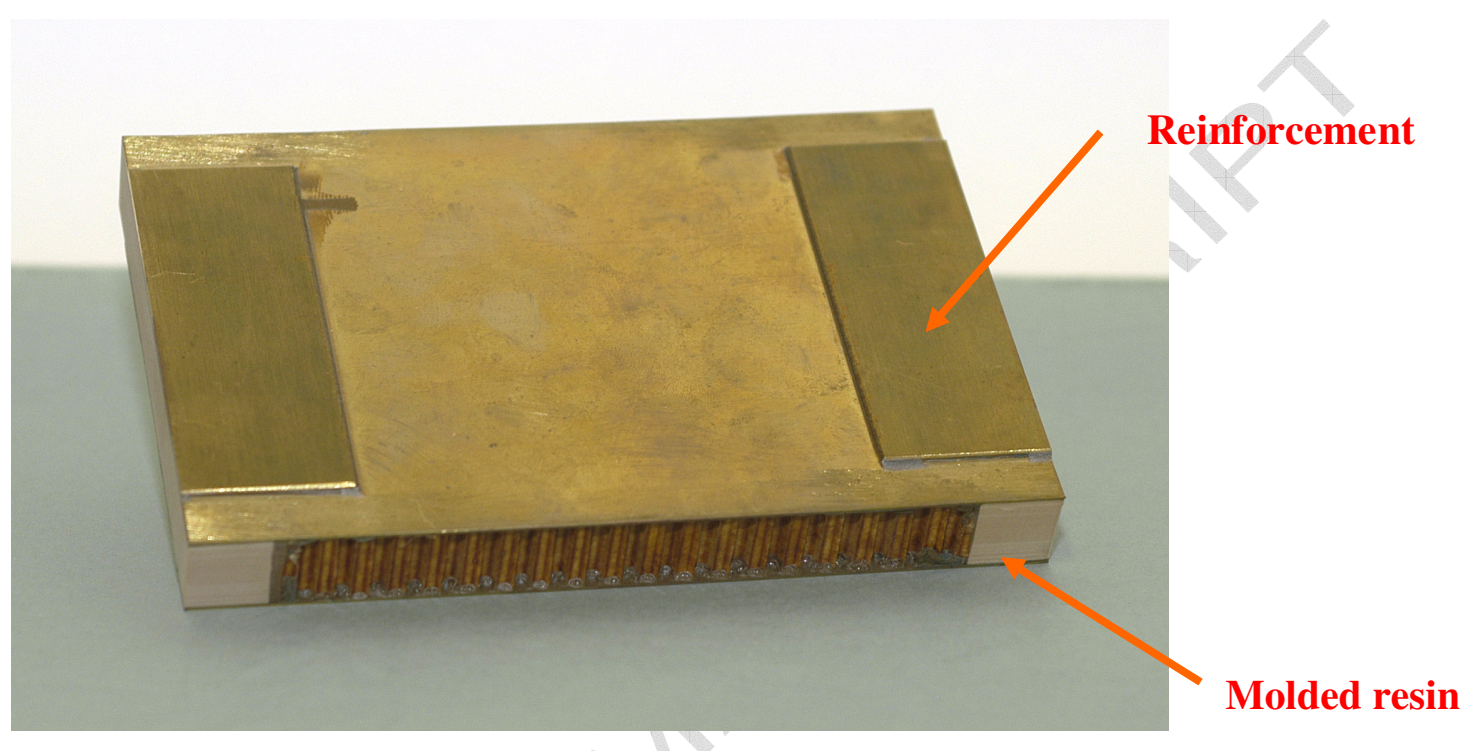

Figure 1: Specimen for CAI tests 


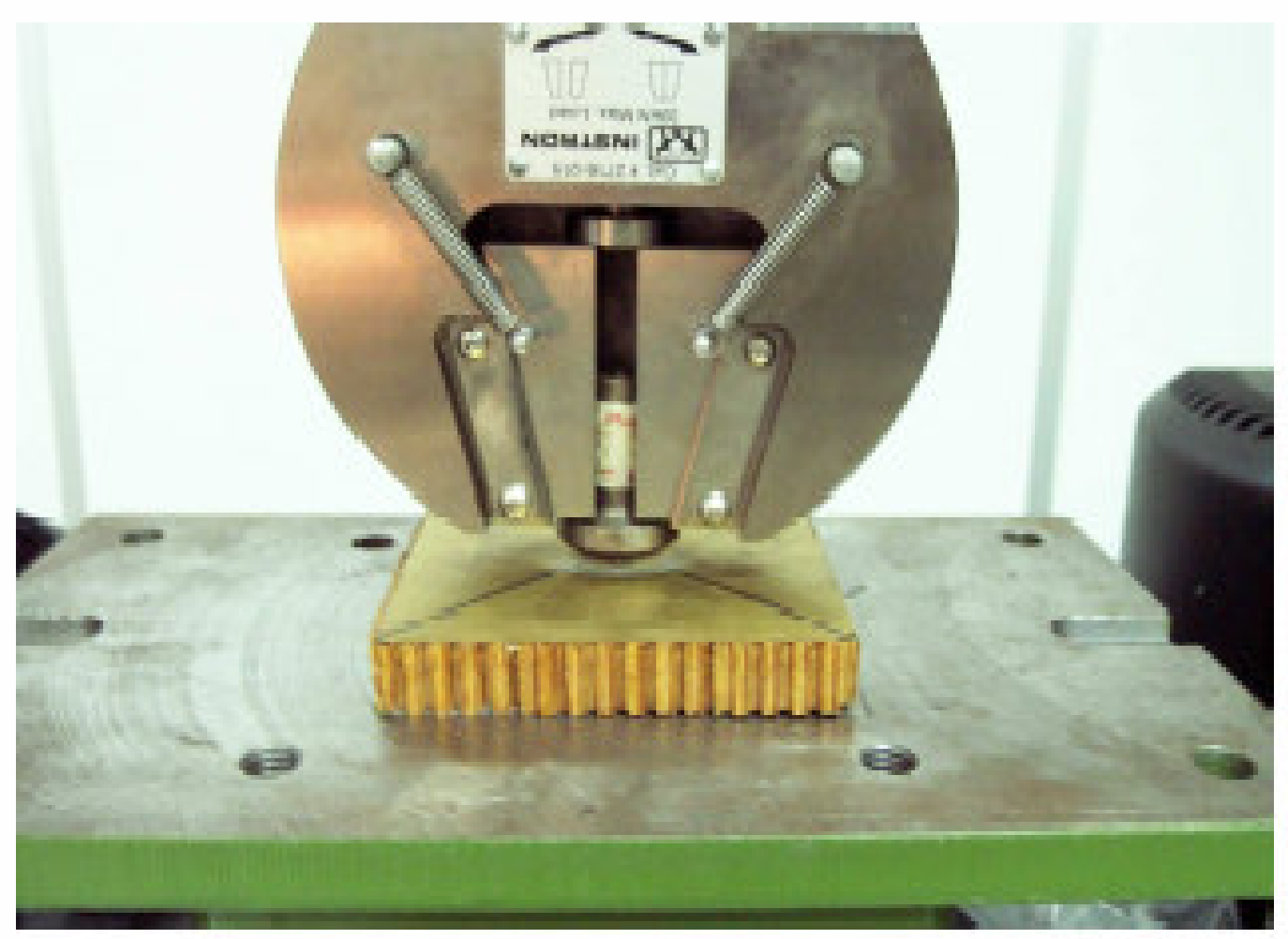

Figure 2 : Static indentation of the CAI specimens.

\section{Compresssion test machine}

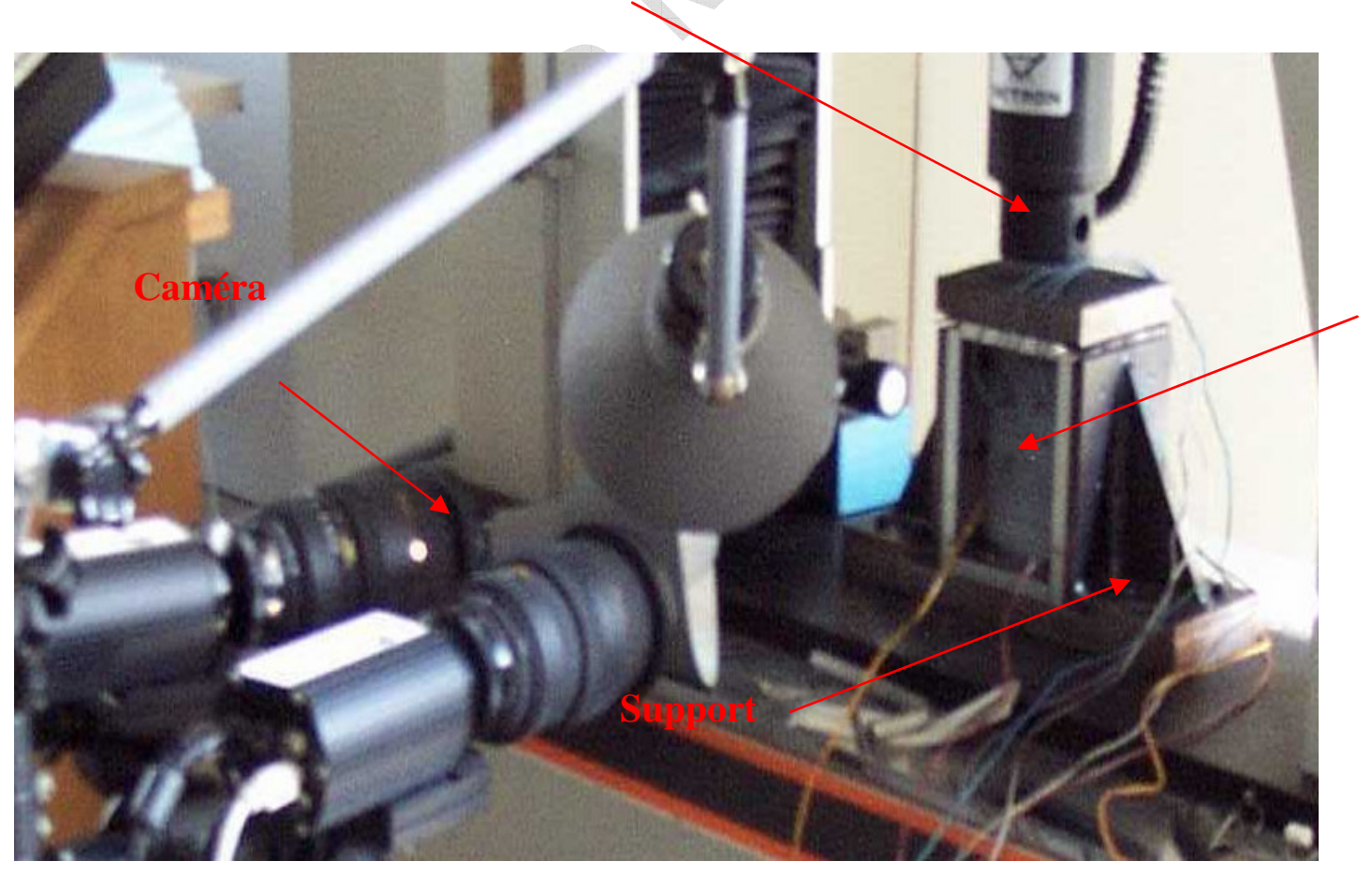

Specimen

Figure 3 : Test device 


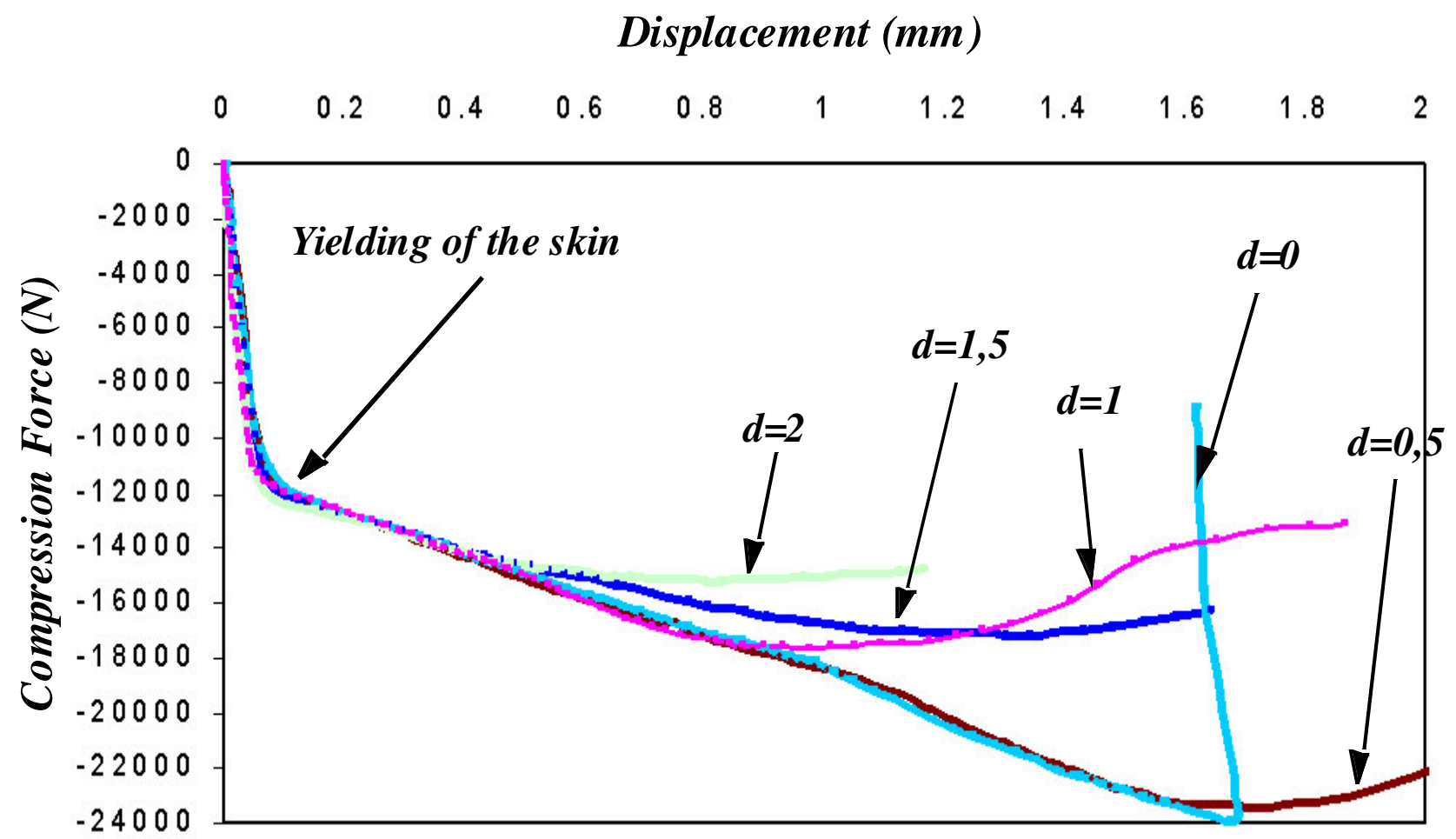

Figure 4 : Compression force versus displacement for different indentation depths d. 


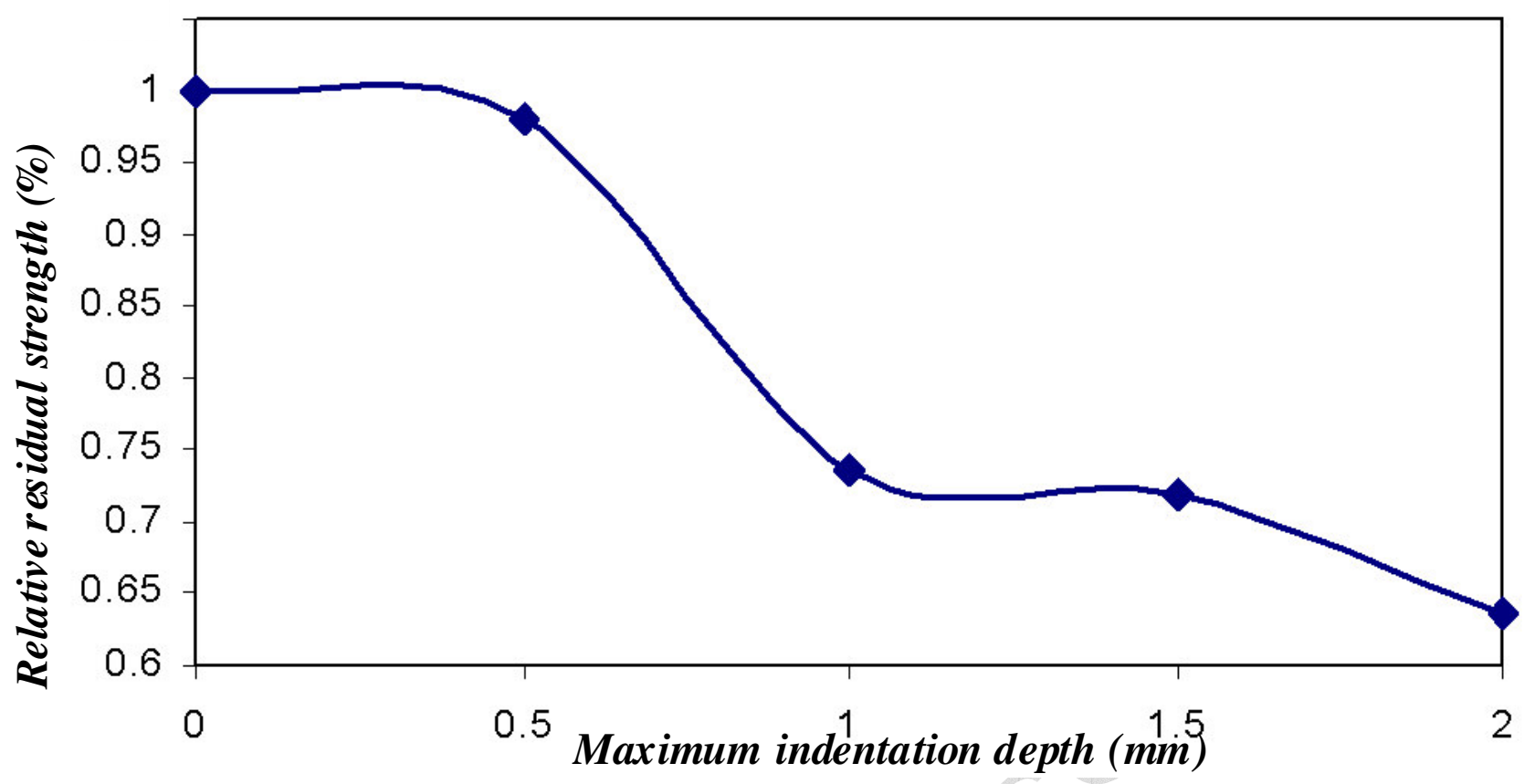

Figure 5 : Relative residual strength function of indentation depth. 


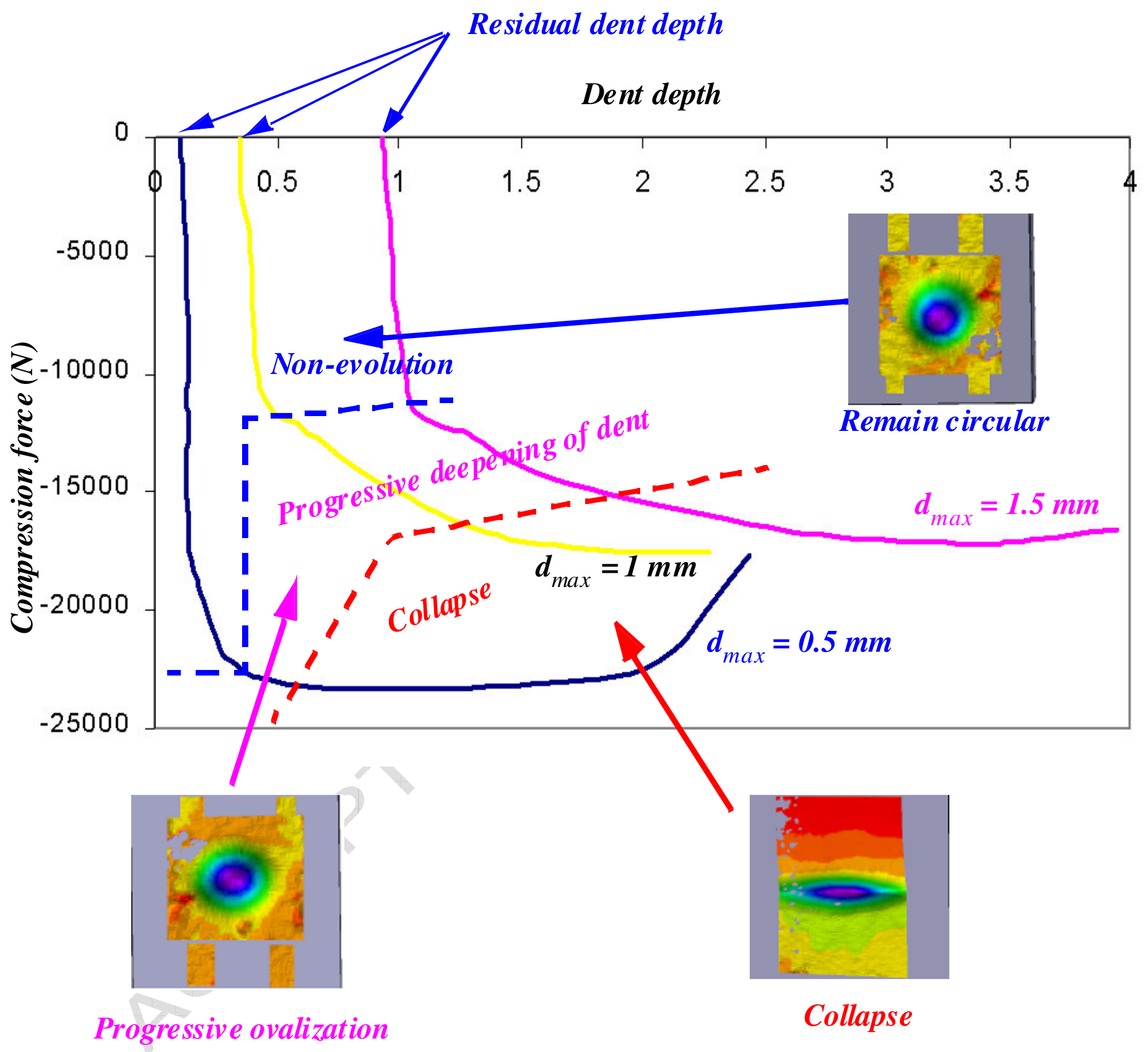

Figure 6 : Evolution of the dent under compression-after-impact loading for maximum dent $d_{\max }$ of $0.5,1$ and $1.5 \mathrm{~mm}$ 


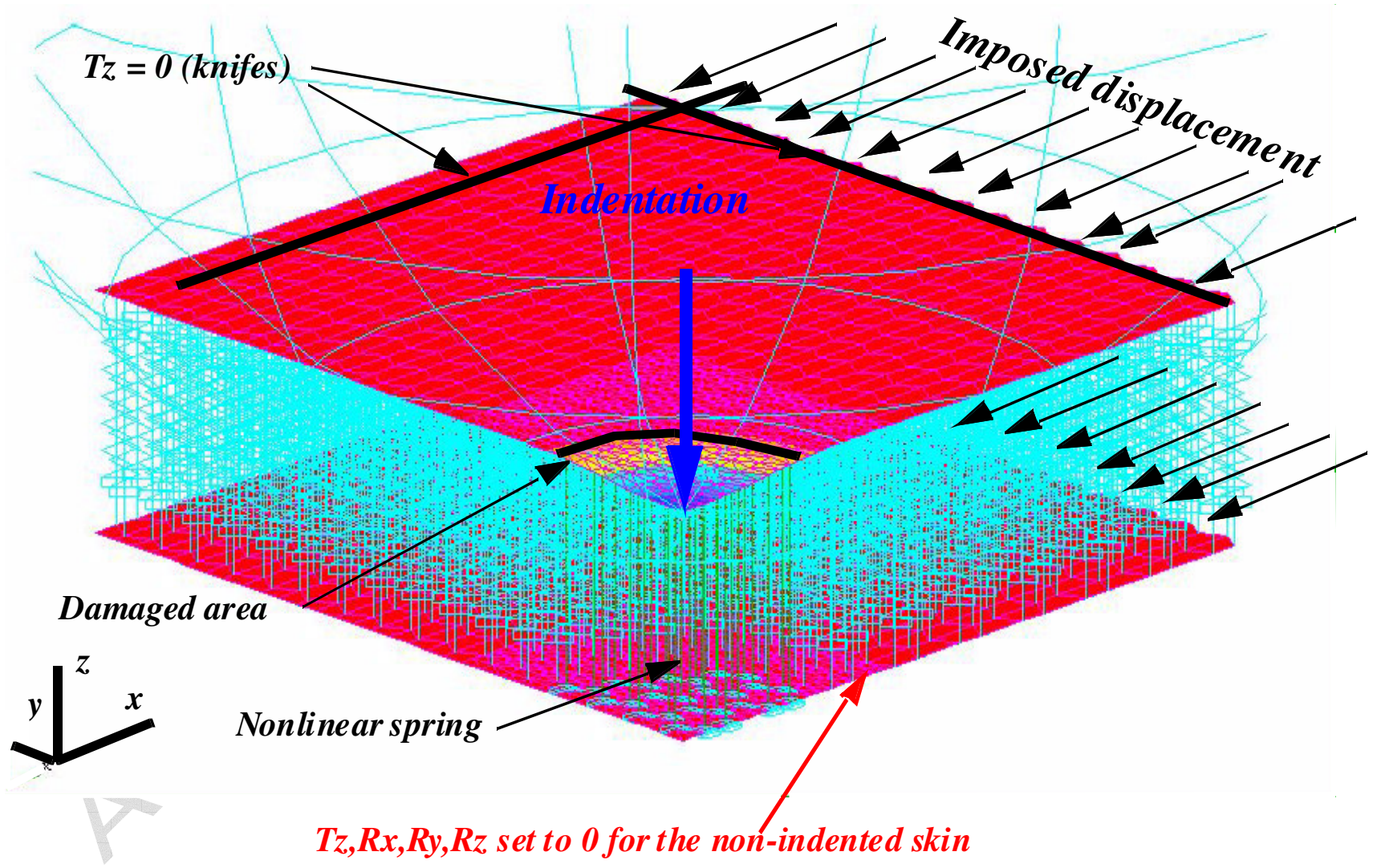

Figure 7 : Finite element model for compression-after-impact. 


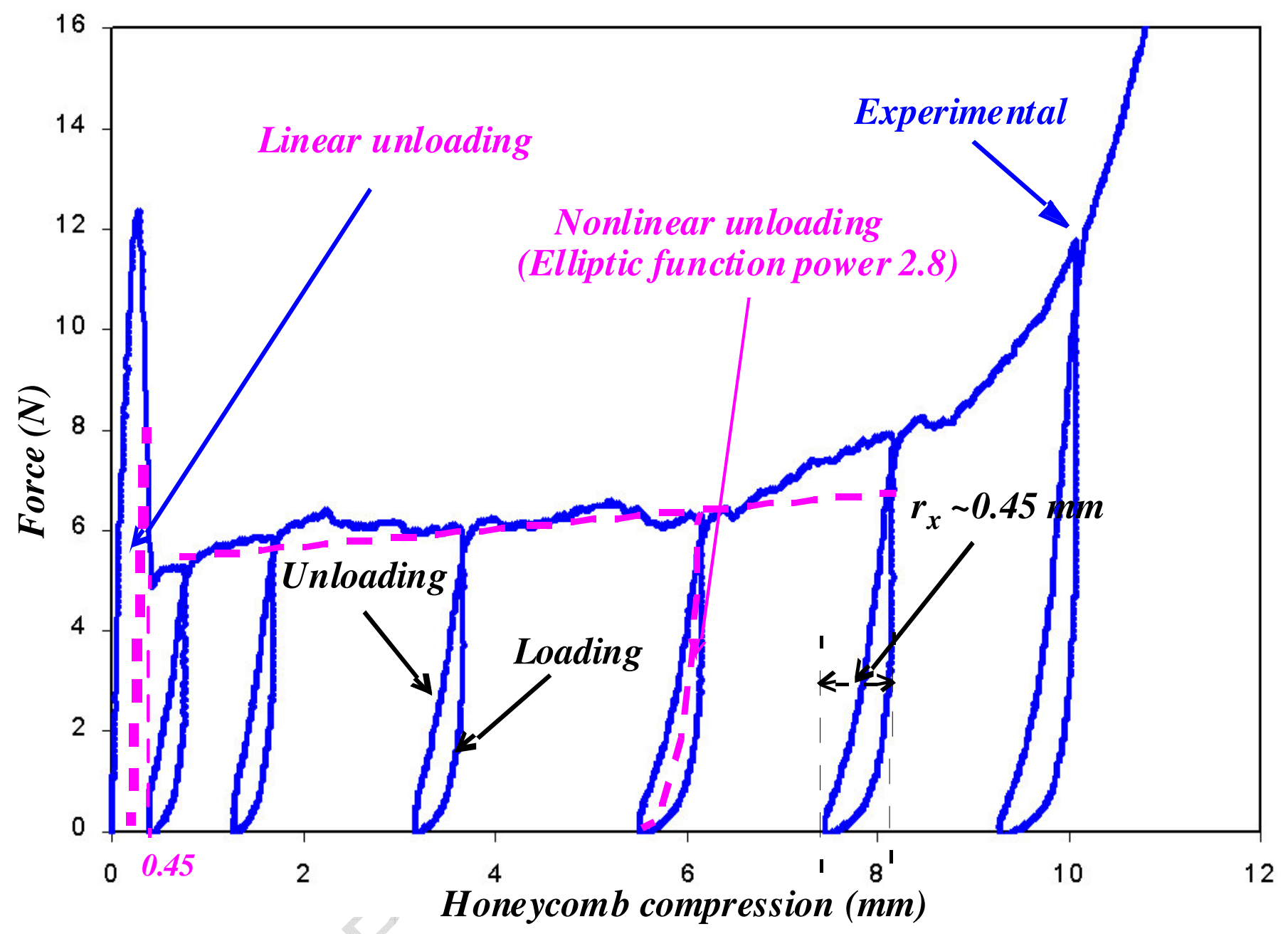

Figure 8 : Compression behaviour of Nomex honeycomb with cycling. 


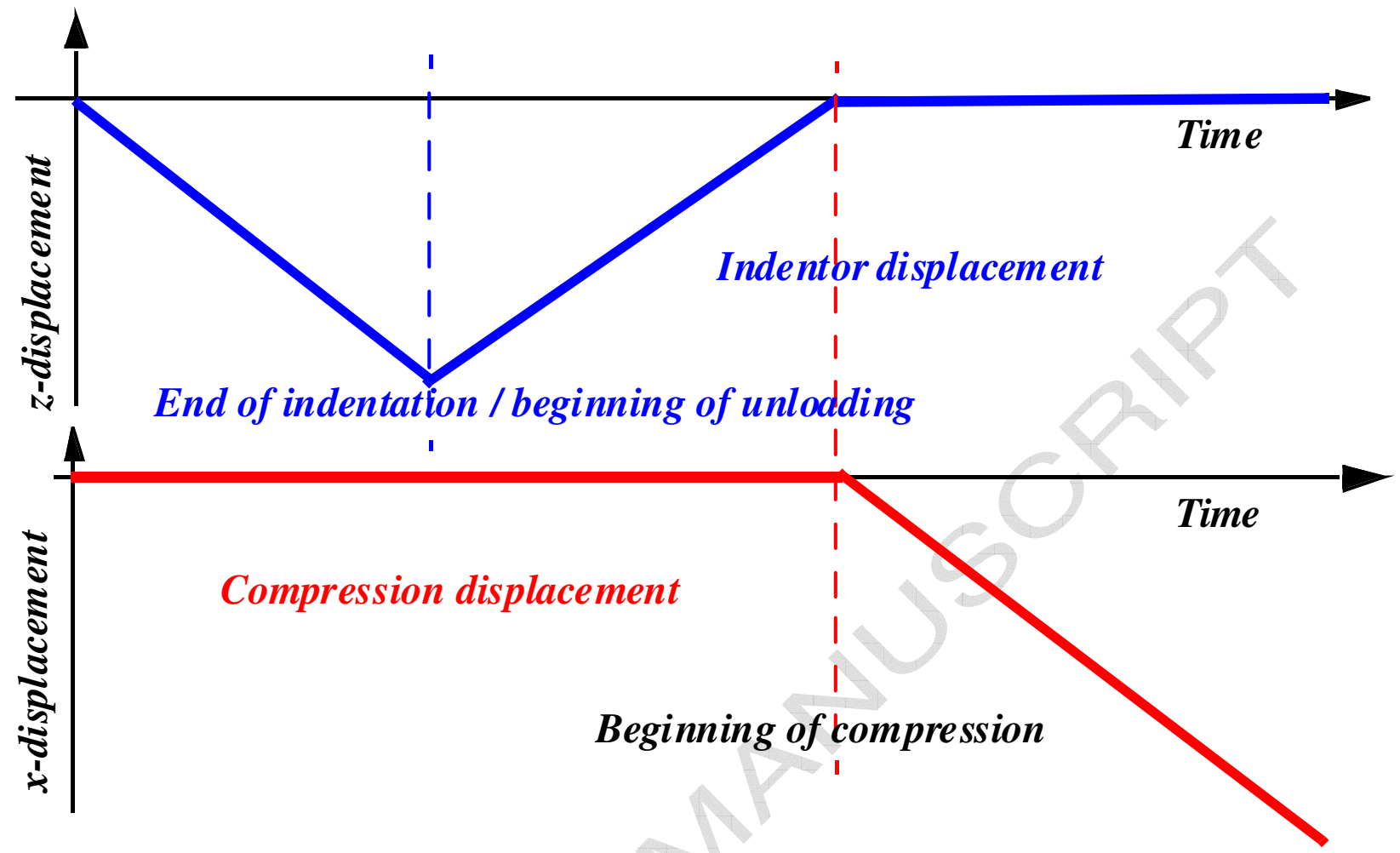

Figure 9 : Time-function displacement laws for compression-after-impact modelling 


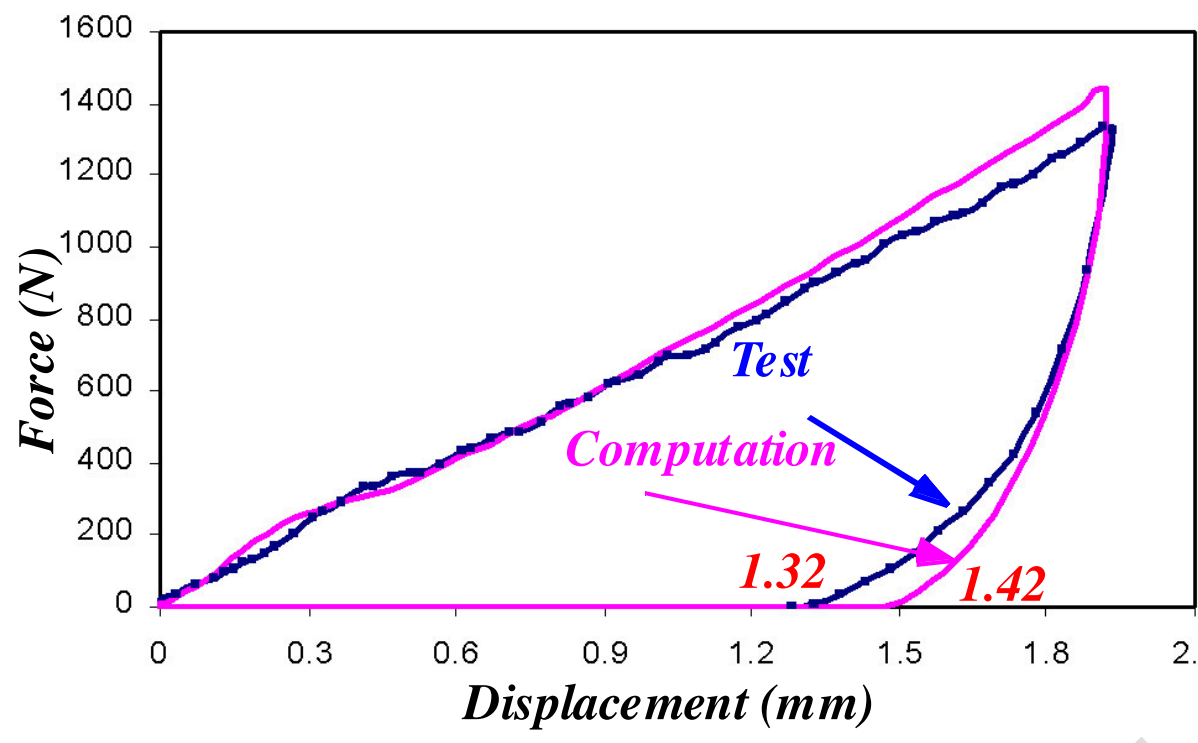

(a)

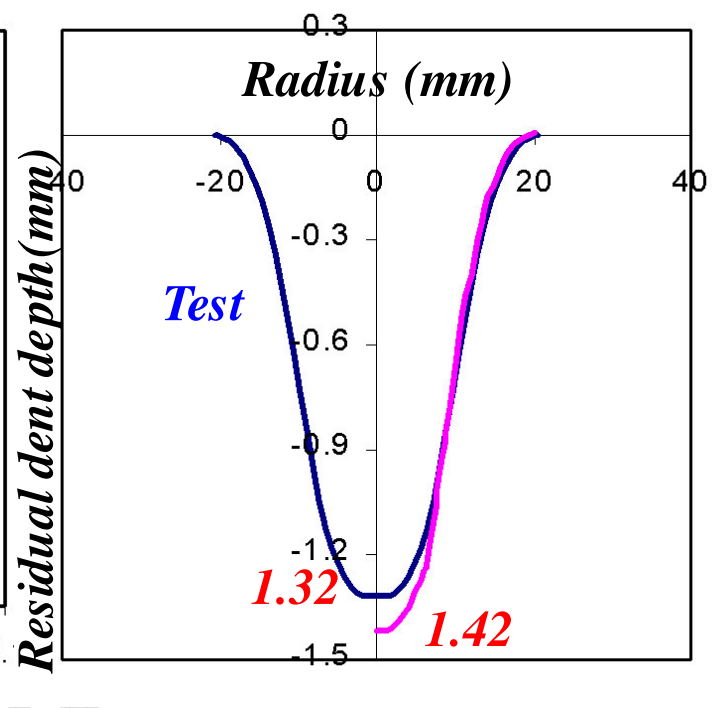

(b)

Figure 10 : Contact law and residual dent test compared with computation for a maximum indentation of $2 \mathrm{~mm}$. 

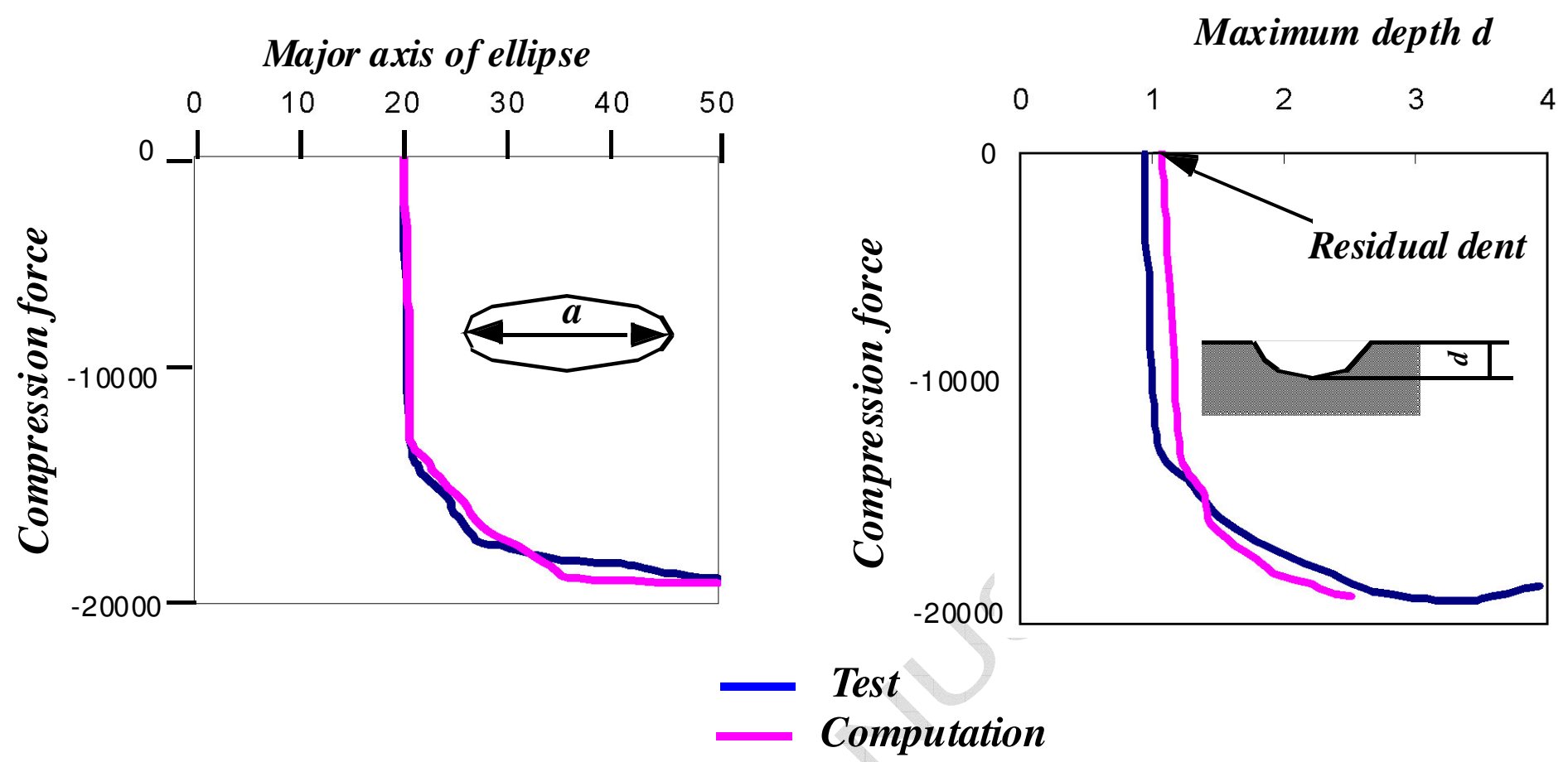

Figure 11 : Correlation of the shape evolution of the dent during the compression for the maximum indentation depth of $1.5 \mathrm{~mm}$. 

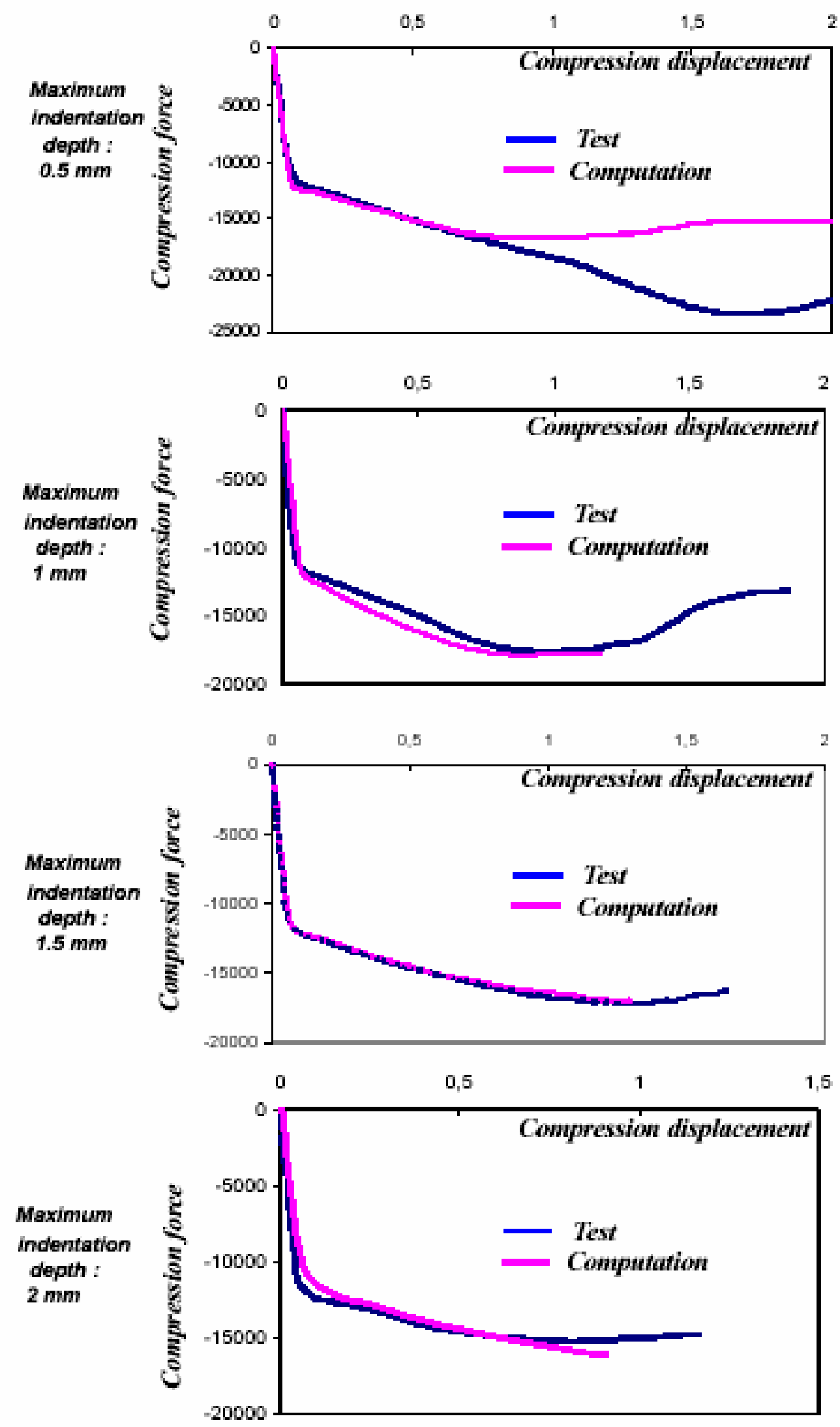

Figure 12: Comparison of compression-after-impact tests and modelling. 


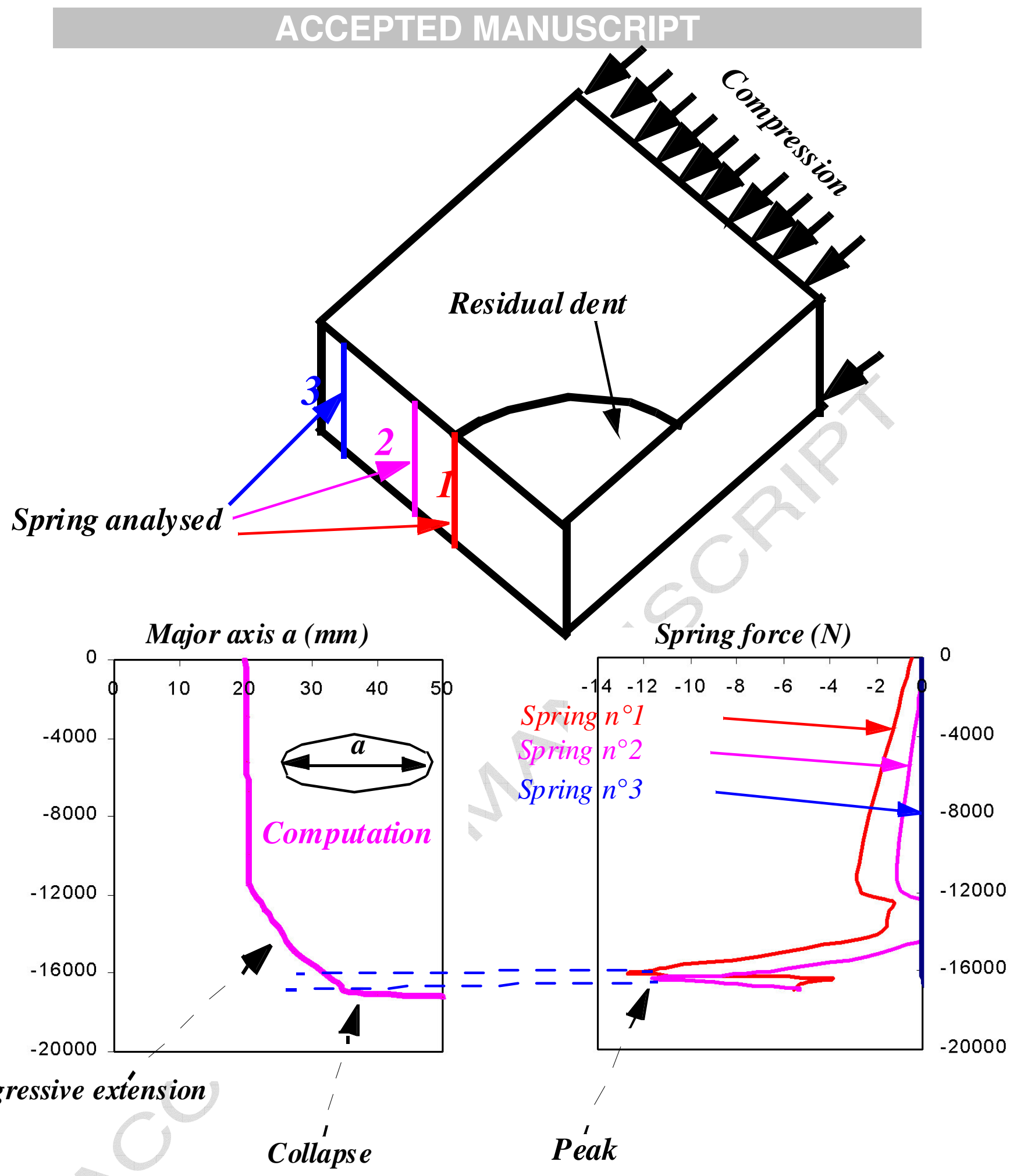

Figure 13 : Analysis of the collapse of the specimen. 


\begin{tabular}{|l|c|c|c|c|}
\hline & Skins & $\begin{array}{c}\text { Honeycomb } \\
\text { core }\end{array}$ & Talon & Reinforcement \\
\hline Material & $\begin{array}{c}\text { Brass, thikness } \\
0.5 \mathrm{~mm}\end{array}$ & $\begin{array}{c}\text { Nomex HRH } \\
78,1 / 4,3 \\
\text { Hauteur } 15 \mathrm{~mm}\end{array}$ & Ureole & Brass thickness \\
& & $1 \mathrm{~mm}$ & \\
\hline
\end{tabular}

Table 1 : Materials characteristics for CAI test specimen. 